\title{
Does all single infarction have lower risk of stroke recurrence than multiple infarctions in minor stroke?
}

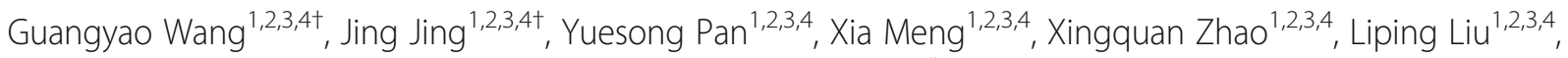
Hao Li $i^{1,2,3,4}$, David Wang ${ }^{5}$, Yongjun Wang ${ }^{1,2,3,4}$, Yilong Wang ${ }^{1,2,3,4^{*}}$ and On behalf of the CHANCE Investigatores

\begin{abstract}
Background: Single acute infarction (SAI) usually had lower risk of stroke recurrence than multiple acute infarctions (MAls) in minor stroke. To evaluate whether all SAI had lower risk of stroke recurrence than MAls in minor stroke.

Methods: We derived data from the imaging subgroup of the Clopidogrel in High-risk Patients with Acute Nondisabling Cerebrovascular Events (CHANCE) trial. Minor stroke were categorized into SAI and MAls by infarction numbers in diffusion weighted imaging. SAI were classified as lacunar infarction and non-lacunar infarction. The outcome was stroke recurrence within one-year follow-up. We assessed the associations between infarction patterns and stroke recurrence using multivariable Cox regression models.

Results: Overall, 834 patients with minor stroke were included in this subgroup, 553 SAI (381 lacunar infarction, 172 non-lacunar infarction) and 281 MAls. The rate of stroke recurrence was $7.6 \%, 15.1 \%$ and $15.3 \%$ in lacunar infarction of SAI, non-lacunar infarction of SAI and MAls at one year, respectively. Compared with MAls, lacunar infarction of SAl had lower risk of stroke recurrence (hazard ratio [HR] 0.41,95\% confidence interval [CI] 0.21-0.80, $P=0.009$ ), but not in non-lacunar infarction of SAI (HR 1.01, 95\% Cl 0.60-1.69, $P=0.98$ ).

Conclusions: Lacunar infarction of SAI have lower risk of stroke recurrence than MAls, while non-lacunar infarction of SAl might have similar risk as MAls. Except for the number of infarctions, size and location should also be considered to stratify risk of stroke recurrence in minor stroke.
\end{abstract}

Trial registration: http://www.clinicaltrials.gov Unique identifier: NCT00979589. Date of registration: September 2009.

Keywords: Minor stroke, Infarction patterns, Prognosis

\section{Background}

Minor stroke are the most common manifestations of acute cerebrovascular disease and the proportion of minor stroke in all ischemic stroke is approximately $50 \%$ [1]. Patients with minor stroke had higher risk of recurrence after symptom onset, especially in the early stage [2]. Recent studies suggested that vascular and neuroimaging parameters may improve risk stratification in minor stroke [3, 4]. TIA registry.org project showed that

\footnotetext{
* Correspondence: yilong528@gmail.com

${ }^{\dagger}$ Guangyao Wang and Jing Jing contributed equally to this work.

'Department of Neurology, Beijing Tiantan Hospital, Capital Medical

University, Beijing, China

${ }^{2}$ China National Clinical Research Center for Neurological Diseases, Beijing,

China

Full list of author information is available at the end of the article
}

infarction patterns helped to stratify the risk of stroke recurrence within one year after minor stroke and patients with multiple acute infarctions (MAIs) had much higher risk of stroke recurrence than that with single acute infarction (SAI) or no acute infarction (NAI), indicating that MAIs was an important imaging marker to predict stroke recurrence [5]. However, several studies showed that there were different patterns in SAI and MAIs respectively corresponding to different stroke etiologies $[6,7]$ or mechanisms $[8,9]$. Different stroke etiologies or mechanisms might lead to different risk of stroke recurrence [10-15]. Traditionally, SAI were classified according to the size and location of the infarction, while MAIs were classified according to the blood supply of different brain areas $[6,7]$. However, it was 
unclear whether different infarction patterns of SAI and MAIs respectively had different risk of stroke recurrence after minor stroke and whether all SAI had lower risk of stroke recurrence than MAIs in minor stroke.

In the current study, deriving data from the imaging subgroup of the Clopidogrel in High-risk Patients with Acute Nondisabling Cerebrovascular Events (CHANCE) trial, we investigated whether among patients with SAI or MAIs whether different infarction patterns were associated with different risk of stroke recurrence. We further compared the risk of stroke recurrence in SAI with different infarction patterns to that of MAIs.

\section{Methods}

\section{Overview of the CHANCE trial}

The detailed design and methods of the CHANCE trial have been previously described $[16,17]$. Briefly, CHANCE was a randomized, double-blind, placebo-controlled clinical trial conducted in 114 centers in China between October 2009 and July 2012. Totally, 5170 patients within $24 \mathrm{~h}$ of non-cardioembolic minor ischemic stroke or high-risk TIA onset were randomly assigned to either clopidogrel plus aspirin (clopidogrel at an initial dose of $300 \mathrm{mg}$, followed by $75 \mathrm{mg}$ per day for 90 days, plus aspirin at 75 mg per day for the first 21 days) or placebo plus aspirin (75 mg per day for 90 days) group. The trial was approved by the Ethics Committee of Beijing Tiantan Hospital and all the participating hospitals. Written informed consent was obtained from all participants or their legal proxies. This study was registered at Clinical Trials.gov (registration number NCT00979589).

\section{Overview of the imaging substudy of the CHANCE trial}

This imaging study was a prespecified substudy of the CHANCE trial. Briefly, 45 (39\%) of 114 centers of the CHANCE trial were prospective recruited in the imaging substudy voluntarily. All patients were asked to complete the magnetic resonance (MR) examinations (3.0 or 1.5 Tesla) during hospitalization in this substudy. Patients with the following MR sequences were included in the substudy: T1-weighted imaging, T2-weighted imaging, diffusion-weighted imaging (DWI), and 3-dimensional (3D) time-of-flight magnetic resonance angiography (MRA). Those without baseline MR examination or any of the above sequences were excluded. The details of the CHANCE imaging substudy have been previously described $[4,18]$.

\section{Patient screening and image analysis}

All MR images collected from individual centers in digital format were read centrally by two readers (X.Z. and J.J.) blinded to the patients' baseline and outcome information. Minor stroke patients with new infarction according to DWI were included in the final analysis. All minor stroke patients were classified as SAI or MAIs according to infarction numbers [5]. Uninterrupted lesions visible in contiguous territories were considered SAI, and more than one lesions topographically distinct (separated in space or discrete on contiguous slices) were defined as MAIs, according to previous DWI studies $[5,19]$. According to previous studies [6, 7], SAI were also classified as lacunar infarction (subcortical lesion with diameter $\leq 15 \mathrm{~mm}$ ) and non-lacunar infarction (subcortical lesion with diameter $>15 \mathrm{~mm}$, cortical lesion and corticosubcortical lesion) and MAIs were classified as 1 . Unilateral anterior circulation; 2. Posterior circulation; 3. Multiple circulations; 4. Border-zone territories (Fig. 1). Any disagreement was decided by a third reader (L.L.).

\section{Etiology classification}

All patients were classified on the basis of The Trial of Org 10,172 in Acute Stroke Treatment (TOAST) classification [20] as previous study [5]. Patients with cardioembolism (CE), systemic disease were excluded in CHANCE, so there were no patients with stroke of CE or other determined pathogenesis subtype. Finally, we devided patients into three TOAST subtypes: large-artery atherosclerosis (LAA), small-artery occlusion (SAO) and stroke of undetermined pathogenesis. Subtype classifications were based on patients' clinical features and the results of one or more diagnostic tests, including brain MR imaging, MRA and extracranial arteries (carotid ultrasound or computed tomograph angiography). All imaging data, clinical features and diagnostic tests results collected from individual centers were reviewed centrally by two study neurologists and gave the subtype classifications.

\section{Follow-up and outcomes}

The original planed follow-up of the CHANCE trial was 90 days. However, we added a visit to follow patients for one year. All of follow-up visits were in person by a trained site coordinator. All reported outcomes were verified by a central adjudication committee which was blinded to the study-group assignments. The outcome was stroke recurrence (ischemic or hemorrhagic) during one-year follow-up [21]. We defined ischemic stroke as an acute focal infarction of the brain or retina with one of the followings: a new focal neurologic deficit lasting for $\geq 24 \mathrm{~h}$, with clinical or imaging evidence of infarction and not ascribed to a nonischemic cause; sudden onset of a new focal neurologic deficit lasting for less than $24 \mathrm{~h}$ and not ascribed to a nonischemic cause, accompanied by new brain infarction on CT or MRI; or rapid worsening of an existing focal neurologic deficit lasting more than $24 \mathrm{~h}$ and not ascribed to a nonischemic cause, accompanied by new ischemic changes on CT or MRI of the brain and visibly distinct from the index ischemic event. We defined 


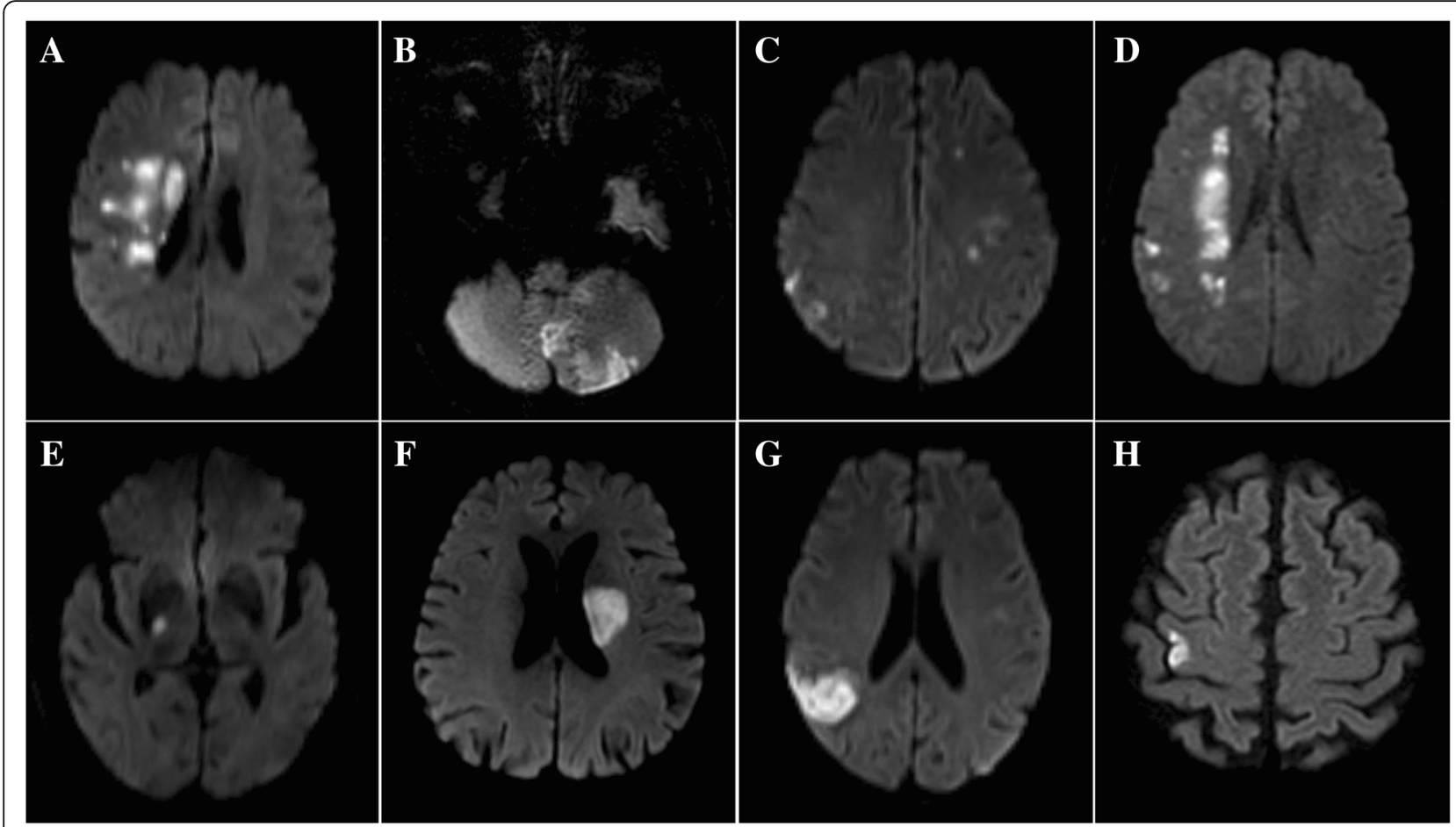

Fig. 1 Infarction patterns of single acute infarction and multiple acute infarctions. Multiple acute infarctions. a Unilateral anterior circulation; b Posterior circulation; c Multiple circulations; d Border-zone territories. Single acute infarction. e Subcortical lesion with diameter $\leq 15 \mathrm{~mm}$; f Subcortical lesion with diameter > $15 \mathrm{~mm} ; \mathbf{g}$ Corticosubcortical lesion; $\mathbf{h}$ Cortical lesion

hemorrhagic stroke as acute extravasation of blood into the subarachnoid space or brain parenchyma with associated neurologic symptoms [17].

\section{Statistical analysis}

Proportions were used for categorical variables, and medians with interquartile ranges were used for continuous variables. Univariate analyses were performed to compare the baseline characteristics among patients with different infarction patterns using one way analysis of variance or Kruskal-Wallis test for continuous variables and $x^{2}$ test for categorical variables. Time to the event in each imaging group illustrated using Kaplan-Meier curve. We assessed the associations between infarction patterns and stroke recurrence of minor stroke using multivariable Cox regression models. Adjusted hazard ratios (HRs) with 95\% confidence intervals (CIs) were reported. All the potential covariates listed in Table 1 were included in the model. All tests were two-sided, and a $P$ value $<0.05$ was considered to indicate statistical significance. All statistical analyses were performed with SAS 9.4 (SAS Institute Inc., Cary, NC).

\section{Results}

Among the 5170 patients, 1089 patients undergoing all the MR sequences as required at baseline were included in the CHANCE imaging subgroup. After excluding 255 patients without infarction, a total of 834 patients with minor stroke were included.

Table 1 shows the baseline characteristics of infarction patterns in lacunar infarction of SAI, non-lacunar infarction of SAI and MAIs. MAIs were more likely to be older, have a history of congestive heart failure and be shorter time to randomization of the trial treatment. Lacunar infarction of SAI were more likely to be smokers. Non-lacunar infarction of SAI were more likely to have higher NIHSS on admission. Additional file 1: Table S1 shows the baseline characteristics of different infarction patterns in SAI and MAIs respectively.

Different infarction patterns in SAI (subcortical lesion with diameter $\leq 15 \mathrm{~mm}$, subcortical lesion with diameter $>15 \mathrm{~mm}$, cortical lesion and corticosubcortical lesion) had different risk of stroke recurrence $(7.6 \%$, $16.3 \%, 5.0 \%$ and $20.0 \%$, respectively), however, different infarction patterns in MAIs (unilateral anterior circulation, posterior circulation, multiple circulations and border-zone territories) had no different risk of stroke recurrence $(14.8 \%, 11.8 \%, 19.5 \%$ and $18.5 \%$, respectively) (Additional file 1: Table S2). The risk of stroke recurrence was $7.6 \%, 15.1 \%$, and $15.3 \%$ in patients with lacunar infarction of SAI, non-lacunar infarction of SAI and MAIs at 1 year follow-up, respectively (Table 2). Compared with MAIs, lacunar infarction of SAI had lower 
Table 1 Baseline characteristics of single acute infarction (lacunar infarction and non-lacunar infarction) and multiple acute infarctions

\begin{tabular}{|c|c|c|c|c|}
\hline Characteristics & $\begin{array}{l}\text { Single acute infarction: } \\
\text { lacunar infarction } \\
n=381\end{array}$ & $\begin{array}{l}\text { Single acute infarction: } \\
\text { non-lacunar infarction } \\
n=172\end{array}$ & $\begin{array}{l}\text { Multiple acute } \\
\text { infarctions } \\
n=281\end{array}$ & $P$ value \\
\hline Age,y, median (IQR) & $62.6(54.6-70.5)$ & $61.0(54.1-70.1)$ & $64.8(56.3-73.0)$ & 0.008 \\
\hline Male, n (\%) & $261(68.5)$ & $105(61.0)$ & $193(68.7)$ & 0.17 \\
\hline Body mass index $\left(\mathrm{kg} / \mathrm{m}^{2}\right)$ & $24.5(22.7-26.2)$ & $24.2(22.0-26.6)$ & $24.2(22.0-26.2)$ & 0.37 \\
\hline \multicolumn{5}{|l|}{ Medical history, n (\%) } \\
\hline Ischemic stroke & $63(16.5)$ & $27(15.7)$ & $54(19.2)$ & 0.55 \\
\hline TIA & $5(1.3)$ & $4(2.3)$ & $9(3.2)$ & 0.25 \\
\hline Myocardial infarction & $6(1.6)$ & $4(2.3)$ & $9(3.2)$ & 0.38 \\
\hline Angina & $9(2.4)$ & $0(0.0)$ & $9(3.2)$ & 0.07 \\
\hline Congestive heart failure & $2(0.5)$ & $2(1.2)$ & $10(3.6)$ & 0.009 \\
\hline Hypertension & $243(63.8)$ & $109(63.4)$ & $184(65.5)$ & 0.87 \\
\hline Diabetes mellitus & $77(20.2)$ & $35(20.3)$ & $69(24.6)$ & 0.36 \\
\hline Hypercholesterolaemia & $45(11.8)$ & $20(11.6)$ & $32(11.4)$ & 0.99 \\
\hline Current or previous smoking, n (\%) & $179(47.0)$ & $62(36.0)$ & $129(45.9)$ & 0.046 \\
\hline Time to randomization, n (\%) & & & & 0.025 \\
\hline$<12 \mathrm{~h}$ & $160(42.0)$ & $88(51.2)$ & $145(51.6)$ & \\
\hline$\geq 12 \mathrm{~h}$ & $221(58.0)$ & $84(48.8)$ & $136(48.4)$ & \\
\hline NIHSS on admission, median(IQR) & $2.0(1.0-3.0)$ & $2.0(2.0-3.0)$ & $2.0(1.0-3.0)$ & $<0.001$ \\
\hline TOAST classification, n (\%) & & & & $<0.001$ \\
\hline Large-artery atherosclerosis & $127(33.3)$ & $82(47.7)$ & $183(65.1)$ & \\
\hline Small-artery occlusion & $254(66.7)$ & $0(0.0)$ & $0(0.0)$ & \\
\hline Undetermined cause & $0(0.0)$ & $90(52.3)$ & $98(34.9)$ & \\
\hline Group, n (\%) & & & & 0.54 \\
\hline Aspirin only & $195(51.2)$ & 89 (51.7) & $133(47.3)$ & \\
\hline Clopidogrel+aspirin & $186(48.8)$ & $83(48.3)$ & $148(52.7)$ & \\
\hline \multicolumn{5}{|l|}{ Medications, n (\%) } \\
\hline Antihypertensive & $126(52.5)$ & $52(48.2)$ & $79(42.9)$ & 0.15 \\
\hline Antidiabetic & $37(48.1)$ & $17(48.6)$ & $30(43.5)$ & 0.82 \\
\hline Lipid-lowering & $25(56.8)$ & $14(70.0)$ & $20(62.5)$ & 0.60 \\
\hline
\end{tabular}

IQR Interquartile range, NIHSS National Institutes of Health Stroke Scale, TOAST Trial of Org 10,172 in Acute Stroke Treatment

Table 2 Adjusted HR for stroke recurrence of different infarction patterns in single acute infarction and multiple acute infarctions at one-year follow-up

\begin{tabular}{|c|c|c|c|c|}
\hline \multirow[t]{2}{*}{ Infarction patterns } & \multirow[t]{2}{*}{$\mathrm{n}$} & \multicolumn{3}{|c|}{ Stroke recurrence at one year } \\
\hline & & $\mathrm{n}(\mathrm{n} \%[95 \% \mathrm{Cl}])$ & Adjusted HR $(95 \% \mathrm{Cl})^{\mathrm{a}}$ & $P$ value \\
\hline Single and multiple acute infarctions & 834 & $98(11.8[9.64-14.13])$ & & \\
\hline Multiple acute infarctions & 281 & $43(15.3$ [11.30-20.05]) & Ref & \\
\hline Single acute infarction: lacunar & 381 & $29(7.6[5.16-10.75])$ & $0.41(0.21-0.80)$ & 0.009 \\
\hline Single acute infarction: non-lacunar & 172 & $26(15.1[10.12-21.36])$ & $1.01(0.60-1.69)$ & 0.98 \\
\hline
\end{tabular}

$H R$ hazard ratio, $\mathrm{Cl}$ confidence interval

${ }^{a}$ Adjusted for: age, sex, body mass index, history of ischemic stroke, TIA, myocardial infarction, angina, congestive heart failure, hypertension, diabetes mellitus, hypercholesterolaemia, smoking status, time to randomization, National Institutes of Health Stroke Scale on admission, Trial of Org 10,172 in Acute Stroke Treatment classification, group, antihypertensive medications, antidiabetic medications and lipid-lowering medications 
risk of stroke recurrence (HR 0.41, 95\% CI 0.21-0.80, $P=$ 0.009 ), but not in non-lacunar infarction of SAI (HR 1.01, 95\% CI 0.60-1.69, $P=0.98$ ) (Table 2). The Kaplan-Meier curves shows the recurrent stroke rate of SAI (lacunar and non-lacunar infarction) and MAIs, respectively (Fig. 2).

\section{Discussion}

In this subgroup analysis of CHANCE, we found that lacunar infarction of SAI had lower risk of stroke recurrence than MAIs, while non-lacunar infarction of SAI might have similar risk as MAIs within one-year follow-up.

TIA registry.org project showed MAIs had higher stroke recurrence than SAI in TIA or minor stroke [5]. However, former studies indicated there were more kinds of infarction patterns than that showed in TIA registry.org project $[6,7,14]$. Traditionally, SAI were classified according to the size and location of the infarction while MAIs were classified according to the blood supply of different brain areas [6, 7]. In our study, we found patients with different infarction patterns had different risk of stroke recurrence in SAI but the difference was not observed in MAIs. We inferred that significant difference of etiologies and pathogenesis among distinct infarction patterns led to the results.

Previous studies indicated that SAI with different patterns were usually related to different etiologies and pathogenesis. Lacunar infarction of SAI usually related to SAO with pathogenesis as 'fibrinoid necrosis' or 'lipohyalinosis' of small perforating arteries [22-24]. SAI with subcortical lesion with diameter $>15 \mathrm{~mm}$ usually related to large-artery atherosclerosis, cryptogenic and cardioembolic diseases $[6,7]$ with pathogenesis as obstruction of the origins of penetrating arteries by parent large intracranial artery intimal plaques or embolism [25-27]. Furthermore, SAI with corticosubcortical lesion or cortical lesion were usually related to LAA, CE and cryptogenic with pathogenesis of embolism $[8,9,14]$. In a word, lacunar infarction was different from non-lacunar infarction in aspect of etiologies and pathogenesis [28]. Traditionally, lacunar infarction usually had a favorable outcome among different TOAST classification $[11,12]$ and lacunar infarction had a favorable outcome when compared with non-lacunar infarction [29-31]. So the above findings could explain the different risk of stroke recurrence in different patterns of SAI for different etiologies and pathogenesis.

Previous studies indicated MAIs were usually related to LAA, CE and cryptogenic, according to the TOAST classification [6, 7]. There was evidence showed that the pathogenesis of MAIs was likely to be caused by the embolism from heart or major extracranial/intracranial vessels [6, 7, 32, 33]. Hemodynamic failure and microem bolization were the pathogenesis of border-zone infarctions [34]. As embolism was the most common

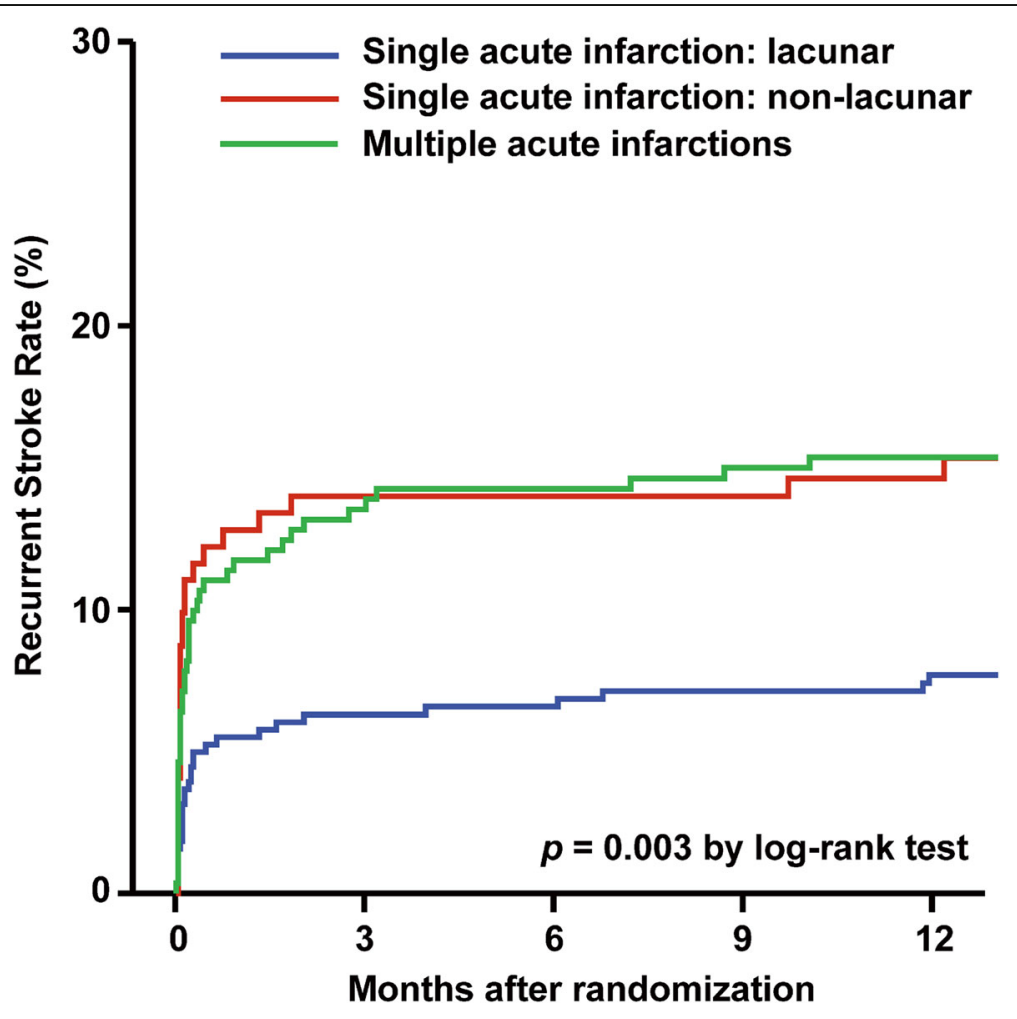

Fig. 2 Stroke recurrence of single acute infarction (lacunar and non-lacunar infarction) and multiple acute infarction 
pathogenesis of MAIs, the above findings could explain the high and similar risk of stroke recurrence in patients with different infarction patterns of MAIs.

Recently, imaging parameters received more attention in order to predict recurrent stroke $[3-5,19]$ and might have better predictive value for stroke recurrence than clinical scores in patients with TIA or minor stroke $[3,35]$. TIA registry.org project showed it was convenient and quick to stratify the risk of stroke recurrence by infarction numbers (NAI, SAI or MAIs) in clinical practice. However, our study indicated that non-lacunar infarction of SAI might have similar risk of stroke recurrence as MAIs, implying that non-lacunar infarction of SAI could be ignored if we simply stratified the risk of stroke recurrence by infarction numbers. So we should not only concern about the number of infarctions, but also the size and location of infarction in order to predict the risk of stroke recurrence in minor stroke. Improved infarction pattern classifications of TIA and minor stroke should be established in the future large cohort study.

Our study presented several limitations. First, since this imaging subgroup analysis included only a small part of patients of CHANCE, potential selection bias might have existed. Second, potential bias might have existed, as apparent diffusion coefficient was not included for evaluating infarction. Third, all patients in this imaging substudy were non-cardioembolic minor ischemic stroke which limited the generalizability of the findings to cardioembolic minor ischemic stroke.

\section{Conclusions}

Lacunar infarction of SAI had lower risk of stroke recurrence than MAIs, while non-lacunar infarction of SAI might have similar risk as MAIs. Except for the number of infarctions, the size and location of the infarction should also be considered to stratify the risk of stroke recurrence in minor stroke.

\section{Additional file}

Additional file 1: Table S1. Baseline characteristics of different infarction patterns in single acute infarction and multiple acute infarctions respectively. Table S2. Adjusted HR for stroke recurrence of different infarction patterns in single acute infarction and multiple acute infarctions at one-year follow-up. (DOCX $31 \mathrm{~kb}$ )

\section{Abbreviations}

3D: 3-dimensional; CE: Cardio embolism; CHANCE: Clopidogrel in High-risk Patients with Acute Nondisabling Cerebrovascular Events; Cl: Confidence interval; DWI: Diffusion-weighted imaging; HR: Hazard ratio; LAA : Largeartery atherosclerosis; MAls: Multiple acute infarctions; MR: Magnetic resonance; MRA: Magnetic resonance angiography; NAl: No acute infarction; SAI: Single acute infarction; SAO: Small-artery occlusion; TOAST: The Trial of Org 10,172 in Acute Stroke Treatment

\section{Acknowledgements}

The authors thank the participants and all who were involved in the CHANCE study.

The CHANCE Investigators

Yongjun Wang, MD (Beijing Tiantan Hospital, Principal Investigator); S.Claiborne Johnston, MD, PhD (Departments of Neurology and Epidemiology, University of California, San Francisco, USA, Co-Principal Investigator); Yilong Wang, MD, PhD (Beijing Tiantan Hospital, Executive Committee); Xingquan Zhao, MD, PhD (Beijing Tiantan Hospital, Site Investigator); Zhimin Wang, MD, PhD (Taizhou First People's Hospital, Site Investigator); Haiqin Xia, MD, PhD (Taiyuan Iron And Steel [Group] Co., Ltd., General Hospital, Site Investigator); (Dagang Oilfield Gengeal Hospital, Site Investigator); Guiru Zhang, MD, PhD (Penglai People's Hospital, Site Investigator); Xudong Ren, MD, PhD (The Third People's Hospital Of Datong, Site Investigator); Chunling Ji, MD, PhD (The Fourth Central Hospital Of Tianjin, Site Investigator); Guohua Zhang, MD, PhD (The Second Hospital Of Hebei Medical University, Site Investigator); Jianhua Li, MD, PhD (The First Hospital Of Fangshan District, Beijing, Site Investigator); Bohua Lu, MD, PhD (Beijing Puren Hospital, Site Investigator); Liping Wang, MD, PhD (Tianjin Ninghe District Hospital, Site Investigator); Shutao Feng, MD, PhD (The People's Hospital Of Zhengzhou, Site Investigator); Dali Wang, MD, PhD (Affiliated Hospital Of North China Coal Medical College, Site Investigator); Weiguo Tang, MD, PhD (Zhejiang Zhoushan Hospital, Site Investigator); Juntao Li, MD, PhD (Han Dan Central Hospital, Site Investigator);

Hongtian Zhang, MD, PhD (Zhecheng People's Hospital, Site Investigator); Guanglai Li, MD, PhD (Shanxi Medical University Second Hospital, Site Investigator); Baojun Wang, MD, PhD (Baotou Central Hospital, Site Investigator); Yuhua Chen, MD, PhD (The General Hospital Of Changjiang River Shipping, Site Investigator); Ying Lian, MD, PhD (Dalian Economic And Technological Development Zone Hospital, Site Investigator); Bin Liu, MD, PhD (First Neurology Department, Affiliated Hospital Of North China Coal Medical College, Site Investigator); Junfang Teng, MD, PhD (The First Affiliated Hospital Of Zhengzhou University, Site Investigator); Rubo Sui, MD, PhD (First Affiliated Hospital Of Liaoning Medical, Site Investigator); Lejun Li, MD, PhD (Lianyungang Municipal Hospital Of TCM, Site Investigator); Zhiling Yuan, MD, PhD (Central Hospital In Qiu County, Site Investigator); Dawei Zang, MD, PhD (Tianjin First Center Hospital, Site Investigator); Zuneng Lu, MD, PhD (Renmin Hospital Of Wuhan University, Site Investigator); Li Sun, MD, PhD (Qingdao Central Hospital, Site Investigator); Dong Wang, MD, PhD (Baogang Hospital, Site Investigator); Liying Hou, MD, PhD (Changzhi City People's Hospital Of Shanxi Province, Site Investigator); Dongcai Yuan, MD, PhD (HaLixun International Peace Hospital, Site Investigator); Yongliang Cao, MD, PhD (People's Hospital Of Linzi District, Zibo, Site Investigator); Hui Li, MD, PhD (Yantai City Yantai Mountain Hospital, Site Investigator); Xiuge Tan, MD, PhD (Beijing Pinggu District Hospital, Site Investigator); Huicong Wang, MD, PhD (Taiyuan Central Hospital, Site Investigator); Haisong Du, MD, PhD (Chengde Central Hospital, Site Investigator); Mingyi Liu, MD, PhD (Shijiazhuang Central Hospital, Site Investigator); Suping Wang, MD, PhD (First Neurology Department, Dalian Municipal Central Hospital, Site Investigator); Qiuwu Liu, MD, PhD (Xian 141 Hospital, Site Investigator); Zhong Zhang, MD, PhD (Chengdu Third Municipal People's Hospital, Site Investigator); Qifu Cui, MD, PhD (Affiliated Hospital Of Chifeng University, Site Investigator); Runqing Wang, MD, PhD (Zhengzhou Central Hospital, Site Investigator); Jialin Zhao, MD, PhD (Ningbo City, Zhejiang Province Lihuili Hospital Medical Center, Site Investigator); Jiewen Zhang, MD, PhD (Henan Provincial People's Hospital, Site Investigator); Jianping Zhao, MD, PhD (Jinzhong City Second Hospital, Site Investigator); Qi Bi, MD, PhD (Beijing Anzhen Hospital, Capital Medical University, Site Investigator); Xiyou Qi, MD, PhD (Beijing Huairou District Chinese Medicine Hospital, Site Investigator); Junyan Liu, MD, PhD (Hebei Medical University Third Hospital, Site Investigator); Changxin Li, MD, PhD (First Affiliated Hospital Shanxi Medical Unversity, Site Investigator); Ling Li, MD, PhD (Hebei Provincial People's Hospital, Site Investigator); Xiaoping Pan, MD, PhD (Guangzhou First Municipal Peoples Hospital, Site Investigator); Junling Zhang, MD, PhD (Central Hospital In Cangzhou, Site Investigator); Derang Jiao, MD, PhD (The Chinese People's Armed Police Force Medical School Affiliated Hospital, Site Investigator); Zhao Han, MD, PhD (Zhejiang Wenzhou Medical College First Affiliated Hospital, Site Investigator); Dawei Qian, MD, PhD (Jilin Central Hospital, Site Investigator); Jin Xiao, MD, PhD (Anhui Maanshan Central Hospital, Site Investigator); Yan Xing, MD, PhD (Beijing Aviation Industry Central Hospital, Site Investigator); Huishan Du, MD, PhD (Luhe Hospital, Tongzhou District, Beijing, Site Investigator); Guang Huang, MD, PhD (Beijing Fuxing Hospital, Capital Medical University, Site Investigator); Yongqiang Cui, MD, PhD (The 306th Hospital Of P.L.A, Site Investigator); Yan Li, MD, PhD (The First Affiliated Hospital Of Tianjin 
University Of Chinese Medicine, Site Investigator); Lianyuan Feng, MD, PhD (Baiqiuen International Peace Hospital Of People's Liberation Army, Site Investigator); Lianbo Gao, MD, PhD (Fourth Affiliated Hospital Of China Medical University, Site Investigator); Bo Xiao, MD, PhD (Xiangya Hospital Central-South University, Site Investigator); Yibin Cao, MD, PhD (Tangshan Worker's Hospital, Site Investigator); Yiping Wu, MD, PhD (The 1st Hospital In Handan, Site Investigator); Jinfeng Liu, MD, PhD (Yangquan Coal (Group) Co., Ltd. General Hospital, Site Investigator); Zhiming Zhang, MD, PhD (Tianjin Tianhe Hospital, Site Investigator); Zhengxie Dong, MD, PhD (Nantong First People's Hospital, Site Investigator); Limin Wang, MD, PhD (The 1st Hospital Of Zhangjiakou City, Site Investigator); Li He, MD, PhD (West China Hospital, Sichuan University, Site Investigator); Xinchen Wang, MD, PhD (The Second Affiliated Hospital Of Shandong University Of TCM, Site Investigator); Xueying Guo, MD, PhD (Fenyang Hospital Of Shanxi Province, Site Investigator); Ming Wang, MD, PhD (Zhejiang Zhoushan Putuo District People's Hospital, Site Investigator); Xiaosha Wang, MD, PhD (Xiyuan Hospital Of China Academy Of Chinese Traditional Medicine, Site Investigator); Jiandong Jiang, MD, PhD (No.2 People's Hospital East In Lianyungang City, Site Investigator); Renliang Zhao, MD, PhD (Affiliated Hospital Of Qingdao University Medical College, Site Investigator); Shengnian Zhou, MD, PhD (Qilu Hospital Of Shandong University, Site Investigator); HaoHu, MD, PhD (Zibo Hospital Of Traditional Chinese Medicine, Site Investigator); Maolin He, MD, PhD (Beijing Shijitan Hospital, Site Investigator); Fengchun Yu, MD, PhD (Beijing Haidian Hospital, Site Investigator); Quping Ouyang, MD, PhD (Beijing Shunyi District Hospital, Site Investigator); Jingbo Zhang, MD, PhD (Dalian Third Municipal Hospital, Site Investigator); Anding Xu, MD, PhD (The First Affliated Hospital Of Jinan University, Site Investigator); Xiaokun Qi, MD, PhD (Navy Genaral Hospital Of P.L.A, Site Investigator); Lei Wang, MD, PhD (Beijing Second Artillery General Hospital, Site Investigator); Fuming Shi, MD, PhD (Beijing Daxing District Hospital, Site Investigator); Fuqiang Guo, MD, PhD (Sichuan Province People's Hospital, Site Investigator); Jianfeng Wang, MD, PhD (Dalian Municipal Central Hospital, Site Investigator); Fengli Zhao, MD, PhD (The Second Hospital In Baoding, Site Investigator); Ronghua Dou, MD, PhD (The Hospital Combine Traditional Chinese And Western Medicine In Cang zhou, Site Investigator); Dongning Wei, MD, PhD (The 309th Hospital Of P.L.A, Site Investigator); Qingwei Meng, MD, PhD (Liangxiang Hospital Of Fangshan District, Beijing, Site Investigator); Yilu Xia, MD, PhD (HuaXin Hospital First Hospital Of Tsinghua University, Site Investigator); Shimin Wang, MD, PhD (Tianjin Huanhu Hospital, Site Investigator); Zhangcang Xue, MD, PhD (Shijiazhuang First Hospital, Site Investigator); Yuming Xu, MD, PhD (The First Affiliated Hospital Of Zhengzhou University, Site Investigator); Liping Ma, MD, PhD (Xinzhou City People's Hospital, Site Investigator); Chun Wang, MD, PhD (Sichuan Province People's Hospital Of Deyang City, Site Investigator); Jiang Wu, MD, PhD (First Hospital, Jilin University, Site Investigator); Yifeng Du, MD, PhD (Shandong Provincial Hospital, Site Investigator); Yinzhou Wang, MD, PhD (Fujian Province Hospital, Site Investigator); Lijun Xiao, MD, PhD (Liaoyang City Third People's Hospital, Site Investigator); Fucong Song, MD, PhD (Handan City Center Hospital, Site Investigator); Wenli Hu, MD, PhD (Beijing Chaoyang Hospital, Capital Medical University, Site Investigator); Zhigang Chen, MD, PhD (Beijing University Of Chinese Medicine East Hospital, Site Investigator); Qingrui Liu, MD, PhD (Hebei Medical University Fourth Hospital, Site Investigator); Jiemin Zhang, MD, PhD (The Fourth Affiliated Hospital Of Soochow University, Site Investigator); Mei Chen, MD, PhD (Zhejiang University Of Chinese Medicine Affiliated First Hospital, Site Investigator); Xiaodong Yuan, MD, PhD (Affiliated Hospital Of Kailuan Company Ltd., Site Investigator); Zhihui Liu, MD, PhD (Affiliated Hospital Of Weifang Medical University, Site Investigator); Guozhong Li, MD, PhD (The First Hospital Of Harbin Medical University, Site Investigator); Xiaohong Li, MD, PhD (Dalian Friendship Hospital, Site Investigator); Tingchen Tian, MD, PhD (Tianjin Dagang Hospital, Site Investigator).

\section{Funding}

This work was supported by the Ministry of Science and Technology of the People's Republic of China (grant numbers 2015BAI12B04, 2015BAl12B02, 2016YFC0901000, 2016YFC0901001, 2017YFC1307900); and the Beijing Municipal Science and Technology Commission (grant numbers D151100002015001, D151100002015003, Z151100003915117). The fund body took no part in the design of the study and collection, analysis, and interpretation of data and in writing the manuscript.

\section{Availability of data and materials}

The datasets during and/or analysed during the current study available from the corresponding author on reasonable request.

\section{Authors' contributions}

GYW study concept and design, analysis and interpretation of data, drafting of the manuscript. JJ acquisition of data, analysis and interpretation of data, drafting of the manuscript. YSP and $\mathrm{HL}$ acquisition of data, analysis and interpretation of data and revision of the drafting of the manuscript. XM, XQZ and LPL acquisition of data and revision of the manuscript. DW study concept and design, revising the manuscript.

YJW obtaining funding, study concept and design, study supervision or coordination, revision of the drafting of the manuscript. YLW obtaining funding, study concept and design, acquisition of data, analysis and interpretation of data, revision of the drafting of the manuscript. All authors read and approved the final manuscript.

\section{Ethics approval and consent to participate}

Name of the ethics committee is IRB of Beijing Tiantan Hospital, Capital Medical University. Ethics approval number of this study is ky2009-002. The trial was approved by the Ethics Committee of Beijing Tiantan Hospital and all the participating hospitals. Written informed consent was obtained from all participants or their legal proxies.

\section{Consent for publication}

In the patient informed consent were stated that all collected data will be analyzed and prepared for publications. All patients gave signed informed consent prior to inclusion in the study.

\section{Competing interests}

The author(s) declared no potential conflicts of interest with respect to the research, authorship, and/or publication of this article.

\section{Publisher's Note}

Springer Nature remains neutral with regard to jurisdictional claims in published maps and institutional affiliations.

\section{Author details}

${ }^{1}$ Department of Neurology, Beijing Tiantan Hospital, Capital Medical University, Beijing, China. ${ }^{2}$ China National Clinical Research Center for Neurological Diseases, Beijing, China. ${ }^{3}$ Center of Stroke, Beijing Institute for Brain Disorders, Beijing, China. ${ }^{4}$ Beijing Key Laboratory of Translational Medicine for Cerebrovascular Disease, Beijing, China. ${ }^{5}$ Illinois Neurological Institute Stroke Network, Sisters of the Third Order of St. Francis Healthcare System, University of Illinois College of Medicine, Peoria, USA.

\section{Received: 18 April 2018 Accepted: 4 December 2018}

\section{Published online: 08 January 2019}

\section{References}

1. von Weitzel-Mudersbach P, Andersen G, Hundborg HH, Johnsen SP. Transient ischemic attack and minor stroke are the most common manifestations of acute cerebrovascular disease: a prospective, populationbased study--the Aarhus TIA study. Neuroepidemiology. 2013;40:50-5.

2. Coull AJ, Lovett JK, Rothwell PM, Oxford Vascular S. Population based study of early risk of stroke after transient ischaemic attack or minor stroke: implications for public education and organisation of services. BMJ. 2004; 328:326.

3. Yaghi S, Rostanski SK, Boehme AK, Martin-Schild S, Samai A, Silver B, et al. Imaging parameters and recurrent cerebrovascular events in patients with minor stroke or transient ischemic attack. JAMA Neurol. 2016;73:572-8.

4. Pan Y, Meng X, Jing J, Li H, Zhao X, Liu L, et al. Association of multiple infarctions and ICAS with outcomes of minor stroke and TIA. Neurology. 2017;88:1081-8.

5. Amarenco P, Lavallee PC, Labreuche J, Albers GW, Bornstein NM, Canhao P, et al. One-year risk of stroke after transient ischemic attack or minor stroke. N Engl J Med. 2016;374:1533-42.

6. Wessels T, Wessels C, Ellsiepen A, Reuter I, Trittmacher S, Stolz E, et al. Contribution of diffusion-weighted imaging in determination of stroke etiology. AJNR Am J Neuroradiol. 2006;27:35-9. 
7. Kang DW, Chalela JA, Ezzeddine MA, Warach S. Association of ischemic lesion patterns on early diffusion-weighted imaging with TOAST stroke subtypes. Arch Neurol. 2003;60:1730-4.

8. Wong KS, Gao S, Chan YL, Hansberg T, Lam WW, Droste DW, et al. Mechanisms of acute cerebral infarctions in patients with middle cerebral artery stenosis: a diffusion-weighted imaging and microemboli monitoring study. Ann Neurol. 2002;52:74-81.

9. Lee DK, Kim JS, Kwon SU, Yoo SH, Kang DW. Lesion patterns and stroke mechanism in atherosclerotic middle cerebral artery disease: early diffusionweighted imaging study. Stroke. 2005;36:2583-8.

10. Arsava EM, Helenius J, Avery R, Sorgun MH, Kim GM, Pontes-Neto OM, et al. Assessment of the predictive validity of etiologic stroke classification. JAMA Neurol. 2017;74:419-26.

11. Lovett JK, Coull AJ, Rothwell PM. Early risk of recurrence by subtype of ischemic stroke in population-based incidence studies. Neurology. 2004;62: 569-73

12. Petty GW, Brown RD Jr, Whisnant JP, Sicks JD, O'Fallon WM, Wiebers DO Ischemic stroke subtypes : a population-based study of functional outcome, survival, and recurrence. Stroke. 2000;31:1062-8.

13. Purroy F, Montaner J, Molina CA, Delgado P, Ribo M, Alvarez-Sabin J. Patterns and predictors of early risk of recurrence after transient ischemic attack with respect to etiologic subtypes. Stroke. 2007;38:3225-9.

14. Bang OY, Lee PH, Heo KG, Joo US, Yoon SR, Kim SY. Specific DWI lesion patterns predict prognosis after acute ischaemic stroke within the MCA territory. J Neurol Neurosurg Psychiatry. 2005;76:1222-8.

15. Ko Y, Lee S, Chung JW, Han MK, Park JM, Kang K, et al. MRI-based algorithm for acute ischemic stroke subtype classification. J Stroke. 2014;16:161-72.

16. Wang $Y$, Johnston SC, Investigators $C$. Rationale and design of a randomized, double-blind trial comparing the effects of a 3-month clopidogrel-aspirin regimen versus aspirin alone for the treatment of highrisk patients with acute nondisabling cerebrovascular event. Am Heart J. 2010;160:380-386.e381

17. Wang Y, Wang Y, Zhao X, Liu L, Wang D, Wang C, et al. Clopidogrel with aspirin in acute minor stroke or transient ischemic attack. N Engl J Med. 2013;369:11-9

18. Liu L, Wong KS, Leng $X, P u Y$, Wang $Y$, Jing J, et al. Dual antiplatelet therapy in stroke and ICAS: subgroup analysis of CHANCE. Neurology. 2015;85:1154-62.

19. Wen HM, Lam WW, Rainer T, Fan YH, Leung TW, Chan YL, et al. Multiple acute cerebral infarcts on diffusion-weighted imaging and risk of recurrent stroke. Neurology. 2004;63:1317-9.

20. Adams HP Jr, Bendixen BH, Kappelle LJ, Biller J, Love BB, Gordon DL, et al. Classification of subtype of acute ischemic stroke. Definitions for use in a multicenter clinical trial. TOAST. Trial of org 10172 in acute stroke treatment. Stroke. 1993;24:35-41.

21. Wang Y, Pan Y, Zhao X, Li H, Wang D, Johnston SC, et al. Clopidogrel with aspirin in acute minor stroke or transient ischemic attack (CHANCE) trial: one-year outcomes. Circulation. 2015;132:40-6.

22. Miller Fisher C. Lacunar infarcts - a review. Cerebrovasc Dis. 1991;1:311-20.

23. Lacunes FCM. Small, deep cerebral infarcts. Neurology. 1965;15:774-84

24. Caplan LR. Lacunar infarction and small vessel disease: pathology and pathophysiology. J Stroke. 2015;17:2-6.

25. Jung $\mathrm{S}, \mathrm{Hwang} \mathrm{SH}$, Lee $\mathrm{BC}$. Distinct clinical expressions of striatocapsular infarction according to cortical manifestations. Eur J Neurol. 2004;11:627-33.

26. Lee KB, Oh HG, Roh H, Ahn MY. Can we discriminate stroke mechanisms by analyzing the infarct patterns in the striatocapsular region? Eur Neurol. 2008; 60:79-84.

27. Nicolai A, Lazzarino LG, Biasutti E. Large striatocapsular infarcts: clinical features and risk factors. J Neurol. 1996;243:44-50.

28. Hart RG, Diener HC, Coutts SB, Easton JD, Granger CB, O'Donnell MJ, et al. Embolic strokes of undetermined source: the case for a new clinical construct. Lancet Neurol. 2014;13:429-38.

29. Sacco S, Marini C, Totaro R, Russo T, Cerone D, Carolei A. a populationbased study of the incidence and prognosis of lacunar stroke. Neurology. 2006;66:1335-8

30. Bejot Y, Catteau A, Caillier M, Rouaud O, Durier J, Marie C, et al. Trends in incidence, risk factors, and survival in symptomatic lacunar stroke in Dijon, France, from 1989 to 2006: a population-based study. Stroke. 2008;39:1945-51.

31. Fang XH, Wang WH, Zhang XQ, Liu HJ, Zhang HM, Qin XM, et al. Incidence and survival of symptomatic lacunar infarction in a Beijing population: a 6year prospective study. Eur J Neurol. 2012;19:1114-20.
32. Takahashi K, Kobayashi S, Matui R, Yamaguchi S, Yamashita K. The differences of clinical parameters between small multiple ischemic lesions and single lesion detected by diffusion-weighted MRI. Acta Neurol Scand. 2002:106:24-9.

33. Ferro JM. Patterns of ischaemic cerebral diseases. J Neurol. 2004;251:1-10.

34. Joinlambert C, Saliou G, Flamand-Roze C, Masnou P, Sarov M, Souillard R, et al. Cortical border-zone infarcts: clinical features, causes and outcome. J Neurol Neurosurg Psychiatry. 2012;83:771-5.

35. Nasr DM, Brown RD Jr. The challenges of stroke prediction scores. JAMA Neurol. 2016;73:510-1.
Ready to submit your research? Choose BMC and benefit from:

- fast, convenient online submission

- thorough peer review by experienced researchers in your field

- rapid publication on acceptance

- support for research data, including large and complex data types

- gold Open Access which fosters wider collaboration and increased citations

- maximum visibility for your research: over $100 \mathrm{M}$ website views per year

At BMC, research is always in progress.

Learn more biomedcentral.com/submissions 